\title{
Direitos Coletivos, Meios de Produção e Povos e Comunidades Tradicionais no Brasil
}

Collective Rights, Means of Production and Traditional Peoples and Communities in Brazil

Bruce Gilbert ${ }^{1}$

Recebido em 16/02/2016 e aceito em 13/03/2016.

Resumo: Categorias ocidentais de pensamento e análise social são devidamente acusadas de serem insensíveis, se não abertamente antagonistas, aos povos e comunidades tradicionais, incluindo os movimentos sociais envolvidos em lutas pela terra. Apesar dessas realidades, tentarei demonstrar que a tradição da filosofia ocidental revela, em dois sentidos, um discurso de direitos que é uma ferramenta mais sutil e poderosa do que os praticantes de direitos humanos, por vezes, levam-no a ser. Primeiro, tentarei demonstrar que a tradição de direito (com base na filosofia liberal) busca reconhecer a "irredutibilidade" de indivíduos à vida coletiva, assim, essa tradição tem a sua própria capacidade intrínseca de reconhecer a "irredutibilidade" de povos e comunidades tradicionais à cultura hegemônica dentro da qual eles se acham. Mais ainda, argumentarei que o discurso dos direitos pode, então, tornar-se uma ferramenta conceitual vital para desafiar a cultura dominante. Em segundo lugar, buscarei ligar a tradição dos direitos

1 Professor de Filosofia na Universidade Bishop's, em Sherbrooke, Québec, Canadá. Autor de livro sobre Hegel e Marx, The Vitality of Contradiction, que ganhou o Premio Bienal de Livro da Associação Canadense de Filosofia. Também faz pesquisa sobre os movimentos sociais no Brasil, sobretudo na interação desses movimentos com questões filosóficas, como: direitos humanos, propriedade, cooperação e socialismo. E-mail: bgilbert@ubishops.ca 
a dois elementos fundamentais da filosofia marxista: a propriedade comum dos meios de produção e a teoria de exploração. Os povos e comunidades tradicionais, muitas vezes, controlam os seus próprios meios de produção e, na verdade, são muitas vezes profundamente engajados na luta para defendê-los. Do mesmo modo, o MST e CPT procuram alcançar os meios de produção através das ocupações de terras que não estão cumprindo sua "função social". Em ambos os casos, o controle dos meios de produção é uma condição necessária para a possibilidade da autodeterminação das comunidades. Sem o controle dos meios de produção, os membros das comunidades têm que vender seu poder de trabalho e, assim, se tornam profundamente mais vulneráveis ao poder hegemônico da sociedade dominante. Nesse ponto, emerge uma importante correlação entre noções liberais de direita, a teoria marxista da exploração e a luta dos povos e comunidades tradicionais: a tradição dos direitos humanos deve ser estendida para proteger os indivíduos e as comunidades da exploração capitalista, precisamente para reivindicar que o controle dos meios de produção é em si um direito humano coextensivo ao direito dos povos e comunidades tradicionais à autodeterminação.

Palavras-chave: direitos humanos; direito liberal; direitos coletivos; povos e comunidades tradicionais; exploração.

Abstract: Western categories of thought and social analysis are accused of being insensitive if not overtly hostile to traditional peoples and communities, including social movements involved in the struggle for land. Despite these realities, I will try to show that the Western philosophical tradition reveals, in two ways, a discourse of rights that is a more subtle and powerful tool even than most practitioners of human rights consider them to be. First, I will try to show that since the rights tradition (based in traditional liberal philosophy) seeks to recognize the "irreducibility" of individuals to the collective life of a people, this notion can be extended to include the irreducibility of traditional peoples and communities to the hegemonic culture. More still, the discourse of rights can thus become a conceptual tool to challenge the dominant culture. Second, I will seek to link the tradition of rights with two fundamental elements of Marxist philosophy: common property of 
the means of production and the theory of exploitation. It is often the case that traditional peoples and communities control their own means of production and they are often profoundly engaged in the struggle to defend that control. In the same way, the MST and CPT seem to achieve control of the means of production by means of occupation of land that is not fulfilling its "social function". In both cases, the control of the means of production is a necessary condition for the possibility of the self-determination of these communities. Without control over the means of production these communities become must sell their labour power and thus become far more vulnerable to the hegemonic power of the dominant society. This reveals an important correlation between liberal notions of rights, the Marxist theory of exploitation and the struggles of traditional peoples and communities: the tradition of human rights must be extended to include the protection of individuals and communities from capitalist exploitation, precisely in order to demand that control over the means of production is a human right in itself that is coextensive with the rights of traditional peoples and communities to their own self-determination.

Keywords: human rights, liberal rights, collective rights, traditional peoples and communities, exploitation

\section{INTRODUÇÃO}

Categorias ocidentais de pensamento e análise social são devidamente acusadas de serem insensíveis, se não abertamente antagonistas, aos povos e comunidades tradicionais, incluindo os movimentos sociais envolvidos em lutas pela terra². Por exemplo, o discurso dos direitos é baseado numa noção de vontade singular livre, segundo a qual a vontade não pode ser reduzida aos laços da comunidade e da cultura, como articulado fundamentalmente por Immanuel Kant. Na

2 Gostaria de agradecer a Priscylla Joca, Ricardo Prestes Pazello, Carlos Marés de Souza Filho e a equipe editorial de InSURgência, pela ajuda inestimável na pesquisa e redação desse artigo. 
verdade, o discurso dos direitos individuais é muitas vezes invocado precisamente para proteger a pessoa livre dos poderes repressivos das normas e dos interesses na sociedade em geral. Percebemos, assim, que o discurso dos direitos é muitas vezes cego às comunidades orgânicas e aos laços comunitários profundos das comunidades indígenas, por exemplo. Da mesma forma, essa vontade singular defendida no discurso dos direitos individuais é também tida como portadora da propriedade privada. Mas, essa noção de propriedade, co-extensiva à moda de relações contratuais no capitalismo, é inadequada à natureza de "propriedade" tipicamente compartilhada entre, por exemplo, povos indígenas e movimentos sociais onde camponeses se organizam para lutar pelas mudanças sociais, como em assentamentos do Movimento dos Trabalhadores Rurais Sem Terra (MST) ou da Comissão Pastoral da Terra (CPT). Na verdade, temos que reconhecer que as noções de contrato e direito de propriedade foram frequentemente orientadas para penetrar e minar povos e comunidades tradicionais, para torná-los maleável à economia capitalista e ao individualismo liberal.

Sem duvida, a noção de povos e comunidades tradicionais é, em muitos sentidos, definida por povos hegemônicos. Carlos Marés diz que
"[o] conceito de 'tradicionais' foi construído pelo pensamento moderno eurocêntrico e fortemente influenciado pela visão ca- pitalista de produção e de concepção de mundo. Isso significa que 'tradicionais' são os que não estão inseridos na produção capitalista fundada em contratos, especialmente o do trabalho, que gera a contradição capital/trabalho. A tradição ou costume é a maneira de fazer as coisas e as relações sociais anteriores ao contrato e sem necessidade dele, neste sentido, na visão evolucionista social, 'atrasado'”3.

No entanto, mesmo o discurso da esquerda frequentemente não faz justiça aos povos e comunidades tradicionais e, na pior das hipóteses, esse discurso age como uma força repressiva que os povos e comunidades tradicionais têm que combater. Alguns Marxistas tradicionais,

3 Correspondência privada com Carlos Marés de Souza Filho, 10 dezembro, 2015. 
por exemplo, muitas vezes pensam nos povos e comunidades tradicionais como "primitivos" e, mesmo sendo eles organizados de modo comunitário, a preservação deles é vista como a proteção do que o próprio Marx chamou da "mediocridade universal" (Marx, 1990: 928). Para superar essa mediocridade eles devem se submeter ao processo de modernização capitalista, a fim de prepará-los para a plena participação em uma eventual sociedade sem classes construída em torno do "indivíduo totalmente desenvolvido" (Marx, 1990: 618) e da produção socializada. O próprio capitalismo é o agente desse progresso, superando o que Marx chamou de "idiotice" da vida rural (Marx, 1983: 208). Esse socialismo industrializado tem pouca semelhança com a cultura e economia dos povos e comunidades tradicionais, incluindo os movimentos sociais que lutam pela reforma agrária.

Apesar dessas realidades graves, tentarei demonstrar nesse ensaio que a tradição da filosofia ocidental revela um discurso de direitos que é uma ferramenta mais sutil e poderosa do que os praticantes de direitos humanos, por vezes, levam-no a ser. Defenderei essa afirmação com base em duas linhas proeminentes do pensamento ocidental. Primeiro, tentarei demonstrar que a tradição de direito (com base na filosofia liberal) busca reconhecer a "irredutibilidade" de indivíduos à vida coletiva, assim, essa tradição tem a sua própria capacidade intrínseca de reconhecer a "irredutibilidade" de povos e comunidades tradicionais à cultura hegemônica dentro da qual eles se acham. Mais ainda, argumentarei que o discurso dos direitos pode, então, tornar-se uma ferramenta conceitual vital para desafiar a cultura dominante.

Em segundo lugar, buscarei ligar a tradição dos direitos a dois elementos fundamentais da filosofia marxista: a propriedade comum dos meios de produção e a teoria daexploração. Os povos e comunidades tradicionais, muitas vezes, controlam os seus próprios meios de produção e, na verdade, são muitas vezes profundamenteengajados na luta para defendê-los, como, por exemplo, as comunidades indígenas, os castanheiros, e os pescadores. Do mesmo modo, o e CPT procuram alcançar os meios de produção através das ocupações de terras que não estão cumprindo sua "fun- 
ção social”. Em ambos os casos, o controle dos meios de produção é uma condição necessária para a possibilidade da autodeterminação das comunidades. Sem a terra para comunidades indígenas, sem o mar para pescadores, sem os rios para ribeirinhos e sem as florestas para os castanheiros essas comunidades não têm jeito de se reproduzir e sobreviver. Sem o controle dos meios de produção, os membros das comunidades têm que vender seu poder de trabaIho e, assim, se tornam profundamente mais vulneráveis ao poder hegemônico da sociedade dominante. Nesse ponto, emerge uma importante correlação entre noções liberais de direita, a teoria marxista da exploração e a luta dos povos e comunidades tradicionais: a tradição dos direitos humanos deve ser estendida para proteger os indivíduos e as comunidades da exploração capitalista, precisamente para reivindicar que o controle dos meios de produção é em si um direito humano coextensivo ao direito dos povos e comunidades tradicionais à autodeterminação.

Para defender as suas reivindicações de direitos, povos e comunidades tradicionais tenazmente resistema ferramenta mais debilitante do capitalismo: a exploração da força de trabalho. Uma vez que as comunidades já não possuem os meios de produção elas devem vender sua força de trabalho para as corporações capitalistas e, quando assim o fazem, elas não são apenas inevitavelmente exploradas, mas também sofrem, frequentemente, um golpe fatal em sua autonomia. A autonomia cultural raramente é capaz de se isolar do poder de desintegração do capitalismo. Enfim, o controle dos meios de produção tem que ser um direito humano.

Claro está que essa síntese do pensamento liberal e marxista já é uma transgressão a ambos. Ela transgride o primeiro porque o discurso de direitos para muitos marxistas é, em última análise, a superestrutura ideológica que facilita a exploração capitalista. Bem como ela transgride a tradição liberal porque os direitos individuais e as leis concomitantes de contrato e da propriedade privada têm sido usados para justificar o trabalho assalariado e negar que este é injusto. A chave para essa síntese, no entanto, é que ambas as tradições liberais e marxistas são comprometidos com o mesmo fim: uma sociedade livre 
e justa ${ }^{4}$. Na verdade, então, o caso dos povos e comunidades tradicionais demonstra porque os discursos liberal e marxista podem ser viradosao avesso, a fim de torná-los muito útil para as reivindicações dessas comunidades por justiça. Assim, inicio por delinear o discurso dos direitos e sua interface com certos temas-chave na luta dos povos e comunidades tradicionais, incluindo os movimentos sociais. Após, realizarei o mesmo tipo de análise no que tange a noção de exploração de Marx. Finalmente, concluirei com uma justificação da noção de queos povos e comunidades tradicionais (e, de fato, todos os seres humanos) têm um direito aos meios de produção.

Antes de entrar nos detalhes dessa discussão, no entanto, vou brevemente esclarecer como eu entendo a definição de "povos e comunidades tradicionais". Estou consciente da fluidez e controvérsia ligada a esse termo. O fato de que esse termo tem sido legalmente reconhecido como uma categoria ligada a direitos defensáveis significa que interesses poderosos têm grande interesse na restrição ou marginalização dele. Vamos começar com a definição empregada pelo Primeiro Encontro Nacional de Comunidades Tradicionais, realizado entre 17 e 19 de agosto de 2005. Povos e comunidades tradicionais, assim, incluem "[p]ovos Indígenas, quilombolas, ciganos, pomeranos, afro-religiosos, ribeirinhos, quebradeiras de coco babaçu, seringueiros, pescadores artesanais, caiçaras, castanheiros e povos dos faxinais, dos gerais e dos fundos de pasto" (apud Neto, 2007: 15-16). Consistente com a prática de alguns que trabalham sobre esse tema, no entanto, eu gostaria de incluir movimentos sociais organizados em torno da luta pela reforma agrária, como o MST e CPT, dentro da noção de povos e comunidades tradicionais. Estou consciente de que essa afirmação não é isenta de discordâncias, mas, como restará claro na análise que segue, meu argumento se aplica a povos e comunidades tradicionais e movimentos sociais (sejam ou não considerados pelo leitorsob esse termo). Em alguns casos, existe uma sobreposição simples e direta

4 Um bom argumento na defesa dessa síntese é o de que muitos povos e comunidades tradicionais já são organizados mais ou menos na linha da justiça articulada por Marx na Critica do Programa Gotha, "[d]e cada um segundo suas capacidades, para cada um segundo suas necessidades" (Marx, 1983: 541). 
entre as comunidades tradicionais (entendida no sentido mais restrito do termo) e a luta pela reforma agrária. Por exemplo, o MST ocupou parte do litoral no Ceará para impedir especuladores de turismo de roubar dos pescadores locais o acesso ao mar. Ou ainda, o Movimento Interestadual das Quebradeiras de Coco Babaçu (MIQCB) ou castanheiras no Paraná têm afinidades óbvias com movimentos de luta pela reforma agrária e com os direitos dos trabalhadores rurais. Para Carlos Marés a chave de "povos e comunidades tradicionais" é que eles não tratam a terra e natureza como uma mercadoria a ser comprada e vendida a fim de ser explorada e abandonada. A "tradição" no Brasil é exprimida por comunidades que têm uma relação muito mais íntima, recíproca e cooperativa com a terra e com a natureza ${ }^{5}$. Um membro de um quilombo no Maranhão falou o seguinte em um congresso de advogados e advogadas populares no Brasil: "[n]ão é suficiente dizer que a terra pertence a nós, mas que nós pertencemos à terra." ${ }^{6}$ Essa relação com a natureza e outro ser humano superaria o que Marx chamou de "alienação", incluindo a "alienação da natureza" nos Manuscritos de 1844. Mais tarde nesse ensaio, vou ligar essa noção reciproca e cooperativa de "propriedade" com a noção de Marx da propriedade comum dos meios de produção.

Em geral, então, concordo com o Carlos Marés sobre esse assunto. Povos e comunidades tradicionais

significam os grupos humanos ligados por direitos coletivos em relação à terra, por um lado porque não atribuem valor de troca à terra, isto é, não a consideram uma mercadoria e por isso a consideram coletiva, no mínimo da família, sem a possibilidade ética de se desfazer dela e por outro lado, a existência de uma interação com a natureza no sentido de saber que a produção da terra depende de uma natureza viva. Estas duas coisas são contrárias a formação social e econômica do capitalismo, que

5 Conversação com Carlos Frederico Marés de Souza Filho em 2 dezembro de 2015.

6 Conversação no encontro anual da Rede Nacional de Advogados e Advogadas Populares, Luziânia, Brasil, 28 novembro de 2015. 
tem a terra como mercadoria que tanta mais vale quanto mais vazia estiver, vazia de natureza e de gente. ${ }^{7}$

Se for o caso, então, que os povos e comunidades tradicionais estão defendendo essencialmente formas justas de relacionamento humano, bem como uma relação sustentável e recíproca com a natureza, eles apontam o caminho para precisamente o tipo de futuro que os movimentos sociais como o MST e CPT estão se esforçando para alcançar. Na verdade, se eles apontam para um futuro que é justo e sustentável, eles lançam luz sobre o que deve ser um futuro para toda a humanidade e para o planeta que compartilhamos.

\section{1. "DIREITOS INDIVIDUAIS" E POVOS E COMUNIDADES TRADICIONAIS}

Como Carlos Marés explica em detalhes em O Renascer dos Povos Indígenas Para o Direito, o discurso tradicional dos direitos ocidentais tem sido centrado quase exclusivamente no reconhecimento universal dos direitos das pessoas livres, no cidadão, eno estado (1998: 61-70). Como Marés aponta, a institucionalização dos direitos humanos no estado ocidental é, portanto, intrinsecamente hostil a toda a noção de "povos e comunidades tradicionais", porque uma das características decisivas da maioria, se não todas essas comunidades, é que eles não se percebem em primeiro lugar como átomos com direitos individuais, mas como membros de comunidades orgânicas. O discurso de direito, assim, não reconhece os "direitos" dessas comunidades, mas também não entende o que essas comunidades são em primeiro lugar. De fato, o autor mais intimamente associado com a articulação e defesa dos direitos individuais, o neo-kantiano John Rawls, baseia seu argumento em uma "posição original" a partir da qual podemos determinar a justiça. Para obter essa posição original devemos passar através de um "véu de ignorância", para ser cegos as todas as particularidades

7 Correspondência privada com Carlos Marés de Souza Filho, 10 dezembro, 2015. 
da vida humana: a raça, a classe, a etnia, a riqueza, o sexo, a nacionalidade e assim por diante. Devemos considerar-nos como seres puramente singulares, vontades racionais sem particularidade (Rawls, 1971: 17-22, 136-42). Claro que essas "particularidades" são o que importam para aqueles que lutam para o reconhecimento dos povos e comunidades tradicionais: cultura, identidade, modos tradicionais de trabalho, crenças e práticas espirituais, e muitas outras. Na medida em que o discurso dominante conseguiu reconhecer coletividades, os reformulou como pessoas-jurídicas ou como indivíduos. "A ideia de que todos indivíduos," explique Marés, "estariam convertidos em cidadãos, ou pelo menos de que todo o individuo teria direito a se tornar cidadão, traduzia-se na assimilação, absorção ou integração dos povos culturalmente diferenciados." (Marés, 1998: 63)

É tentador concluir, então, que a tradição de direitos individuais é, do ponta da vista da luta pelo reconhecimento dos povos e comunidades tradicionais, um fracasso sem esperança: mesmo a atribuição de direitos a povos e comunidades tradicionais e a assentados de reforma agrária exige que eles sejam concebidos em termos alienígenas aos da sua própria auto-compreensão. A fronteira entre os povos tradicionais e o mundo do capitalismo liberal aparece como uma aporia entre dois modos de ser que podem, no melhor caso, se tolerar uns aos outros sem verdadeira intimidade ou, no pior caso (que é muito mais próximo da realidade) se envolver em uma luta onde o poder hegemônica tem quase a certeza de ganhar (por exemplo, ver Bourdieu, 1989).

No entanto, quando consideramos o discurso dos direitos nas suas raízes filosóficas, podemos destacar razões de ter uma esperança. Vou argumentar que a tradição do direito individual é muito valiosa pelas lutas pela justiça (incluindo, às vezes, para os povos e comunidades tradicionais), mas também em alguns sentidos essa tradição é filosoficamente rigorosa e politicamente eficaz. O problema não é o discurso dos direitos individuais em si, mas a incapacidade de se estender a lógica do direito à sua própria conclusão adequada.

O que é, de fato, um direito individual? É um acordo que uma comunidade faz com ela mesmo de respeitar certas características do 
indivíduo livre ${ }^{8}$. É apropriado dizer que esse direito surge da vontade singular como irredutível às formações sociais particulares dentro da qual as pessoas se encontram (entidades econômicas, grupos religiosos, famílias, culturas e assim por diante) e a comunidade como um todo. Na verdade, ele trata do individuo singular como irredutível também ao capital, a classe e as estruturas de dominação. Ou seja, uma pessoa livre pode ser um católico, um indígena brasileira, um ribeirinho, uma vítima de coerção ideológica em São Paulo ou um defensor dos poderes do capital, mas ele ou ela não é redutível a nenhuma dessas identidades. Aqui, a tradição filosófica liberal parece apontar para algo verdadeiro, algo muito importante que os seres humanos aprenderam sobre a nossa liberdade. Vimos isso, sobretudo, no direito de pensar e falar livremente. Cada indivíduo singular tem o poder de duvidar e se afastar dos papéis ou identidades culturais, econômicos, políticos ou sociais para se definir de outro jeito. Esse indivíduo livre, vulnerável a aplicação de forças, sobretudo a força dos poderes econômicos e políticos mais hegemônicos, deve ser protegido. O poder que cada ser humano tem de se determinar por si mesmo é fundamental não somente para a tradição dos direitos humanos, mas também para a realização da liberdade humana, incluindo a democracia. De fato, a capacidade de se distinguir da sociedade hegemônica e adotar uma perspectiva critica com respeito a ela é uma manifestação desse poder da autoconsciência humana. Apesar do fato que a autoconsciência livre é reduzida a uma espécie de individualismo atomizado, isso não quer dizer que realmente existe qualquer relação necessária entre os dois. Na verdade, mesmo quando os povos e comunidades tradicionais lutam para serem reconhecidos como comunidades, não querem ter negadoos seus direitos individuais. Se um indígena brasileiro decide separar-se de suas crenças tradicionais, de uma forma ou de outra, muito apropriadamente respeitamoso seu direito pessoal de assim o fazer. O objetivo das lutas por justiça não é o de revogar os di-

8 Por "acordo" aqui eu ando sobre uma linha fina entre a Cila das relações de poder na vida real, onde o direito democrático não é mais do que o interesse dos poderosos imposta aos fracos, e a Caríbdis de direito democrático como um ideal platônico vazio, um "dever-ser" abstrato da vida concreta. No entanto, as democracias devem sempre se esforçar para ser mais democráticas. 
reitos das pessoas singulares que compõem os povos e comunidades tradicionais, mas sim o de estender a luta pelos direitos para incluir um reconhecimento do direito dessas comunidades de se protegem como comunidades, em vez de serem vistas meramente como agregados de pessoas livres. Isso tudo é ainda mais importante com relação às lutas pela terra, onde os trabalhadores rurais individuais ou os membros de comunidades indígenas são muitas vezes individualmente perseguidos. Os seus direitos humanos individuais, conforme articulado na Constituição Federal de 1988, bem como na Declaração Universal dos Direitos Humanos, são, portanto, uma ferramenta vital e permanente em sua defesa. ${ }^{9}$

Porém, quando notamos uma tensão interna na filosofia do direito, podemos mais facilmente perceber porque é da maior importância que a noção de direito não se restrinja a proteger a pessoa singular. Essa tensão foi notada por Hegel na sua critica da filosofia de direito individual de Kant. A tensão interna do discurso dos direitos, o que Hegel chamaria a "contradição vital" da liberdade, começa com o fato que o direito putativo de pessoa singular irredutível não existe de qualquer jeito sem o acordo coletivo de um povo a respeitá-lo (Hegel, 2010: 38185). Ou seja, a "personalidade singular e livre" existe como um fato historicamente emergente da autoconsciência humana que foi somente plenamente reconhecido nos últimos séculos. Enquanto o poder de duvidar das nossas crenças é coextensivo à autoconsciência humana e é assim possível em qualquer momento na história, essa característica da liberdade do indivíduo somente existe na plenitude quando em coletividade, assim, a comunidade como um todo se compromete a reconhecê-lo, cultivá-lo, protegê-lo e executa-lo. Para Hegel, nós aprendemos sobre a nossa liberdade na história. Nota-se, então, essa tensão interna ou contradição produtiva no discurso dos direitos: uma identidade comunitária numa sociedade livre se realiza somente

9 O fato de que os direitos individuais são consagrados nas constituições de muitos estados ou nas Nações Unidas não significa que eles serão aplicados. Por exemplo, as ocupações de terra do MST buscam forçar a aplicação da cláusula "função social" da terra na Constituição Federal de 1988, que havia sido quase completamente ignorada ou subvertida. A luta política é geralmente necessária para que os direitos sejam criados, mas também para que sejam aplicados. 
quando, paradoxalmente (dialeticamente), ela reconhece que as pessoas singulares são irredutíveis a essa própria identidade comunitária. Para colocar isso de outra forma, a irredutibilidade da personalidade singular humana somente é realizada quando ela é universalmente reconhecida, cultivada, apoiada e executada pelas instituições da sociedade - quando se torna um direito.

Os direitos, para desenvolver essa ideia um pouco mais, surgem como resultado da luta dos seres humanos para convencer uns aos outros de aspectos decisivos da nossa liberdade. A luta pelos direitos individuais foi realizada não somente durante as grandes revoluções liberais do século 18 (em Haiti, nos Estados Unidos e na França), mas também pelo movimento dos direitos civis, pelo feminismo, e por muitas outras lutas em todo o mundo. Sem qualquer dúvida, os direitos são, às vezes, somente promulgados quando são casados aos interesses econômicos e políticos (veja a congruência dos direitos humanos com capitalismo, enfatizado por Marx), mas esses direitos nunca podem ser reduzidos a esses poderes e frequentemente são usados para os resistir ${ }^{10}$. Em geral, os direitos não são aspetos abstratos da vontade livre (como em Kant e Rawls), mas são os acordos realizados na história das condições necessárias para nossa liberdade humana. Isso quer dizer que estão sempre num processo de transformação enquanto o processo histórico cria novas realidades. Por exemplo, a crise meio-ambiental combinou com o trabalho de povos indígenas e movimentos sociais para criar, pela primeira vez na história, "direitos da natureza" na nova Constituição de Equador, promulgada em $2008^{11}$.

Voltando a nossa discussão sobre Hegel, a sua crítica a Kant toma mais um passo muito importante. Nenhuma sociedade é um agregado de átomos individuais e nunca é um contrato. Em vez disso, cada sociedade é uma rede de sub-comunidades, de órgãos do corpo-político. Claro, não é um corpo-político no sentido da polis grega,

10 É por isso que a noção de uma vontade livre é uma conquista histórica, mas ainda assim não simplesmente uma "invenção", não meramente uma particularidade das culturas ocidentais que a universaliza artificialmente.

11 Essa noção de direitos humanos, sendo histórico, compartilha muito em comum com a teoria de Jürgen Habermas, menos a ênfase dele sobre a linguagem. Ver Habermas (1996). 
precisamente porque uma sociedade livre também tem que reconhecer o direito individual. Para colocar isso de outro jeito, se cada pessoa singular necessariamente se particulariza quando ela age, os órgãos (particularidades) do corpo político são igualmente válidos e importantes para a filosofia do direito, tanto quanto os indivíduos (singulares) e a comunidade em geral (universal). Para Hegel, não existe um universal puro nem um bem comum puro ${ }^{12}$. Isso quer dizer que a sociedade em geral é nada mais do que Gramsci chamou, em uma ideia bem hegeliana, de luta para a hegemonia dos particulares. Se particularidades, como a classe trabalhadora ou os povos e comunidades tradicionais, querem ter uma voz na sociedade, elas têm que entrar na luta política contra as particularidades dominantes e exigirem o reconhecimento de seu direito.

Em outras palavras, se a coletividade, a comunidade universal, pode reconhecer que as pessoas singulares são irredutíveis às suas próprias formas características de vida, ela pode também reconhecer a irredutibilidade de coletividades específicas, como povos e comunidades tradicionais, incluindo acampamentos e assentamentos da reforma agrária. Essas comunidades fazem, de fato, uma reclamação quanto à sua própria irredutibilidade à sociedade dominante. Se pensarmos em direitos como gestos da sociedade humana para reconhecer o que é irredutível nela mesmo, é completamente consistente com os fundamentos filosóficos dos direitos humanos o respeito às comunidades como também irredutíveis. A concepção e a proteção da irredutibilidade das comunidades à sociedade, em geral, não sinaliza o fracasso do discurso dos direitos, mas é o desenvolvimento rigoroso da sua própria visão do caráter da liberdade humana. Para colocar isso de outra forma, o discurso dos direitos, na sua melhor forma, é

12 Esse ponto parece estar em contradição com o fato de que Hegel defende a universalidade da classe burocrática na Filosofia de Direito. Mas, uma leitura cuidadosa dos textos de Hegel revela que ele nunca acata categorias universais abstratas, com exceção do pensamento abstrato (Verstand). Para Hegel, as categorias de ética, sociedade e política são sempre concretas, e jamais são abstrações platônicas. Quando Hegel fala da atitude universal da burocracia ele quer dizer que ela facilita a conversa de todas as particularidades na sociedade. Como, por exemplo, quando a Constituição brasileira de 1988 reconhece a autodeterminação (irredutibilidade) dos povos indígenas. 
uma lógica de relacionamento humano que reconhece e respeita diferenças, seja de uma autoconsciência singular ou de uma comunidade particular ${ }^{13}$. Quando o governo do Brasil estende o direito de reconhecimento aos povos indígenas, ou para Quilombos, ou para qualquer outra povo ou comunidade tradicional, ele esta cumprindo a essência dos direitos humanos na medida em que reconhece a irredutibilidade dessas comunidades. Na verdade, a noção de uma sociedade livre é incompleta se ela somente reconhece os direitos das pessoas singulares e não das comunidades dentro dela mesma. A luta dos povos e comunidades tradicionais é uma das ações humanas que vem ensinando essa lição à humanidade, em nosso atual momento histórico.

Há, no entanto, uma diferença fundamental entre a forma de exclusividade das comunidades e da exclusividade das pessoas singulares. O caso do MST é, talvez, de todas as comunidades normalmente incluídas nesta categoria, a mais próxima da forma lógica do direito exclusivo da pessoa singular. Apesar das aspirações do MST de superar o estado eas relações capitalistas, num sentido muito importante a ocupação da terra só pode realmente cumprir suas próprias metas uma vez que atinge o reconhecimento do estado - quando um acampamento passa a serum assentamento. A autonomia do assentamento só pode florescer quando o seu direito legal à terra que ocupou é estabelecida, quando ela alcança a segurança necessária em face das ameaças da polícia local, pistoleiros ou autoridades políticas, quando ela recebeo crédito do Instituto Nacional de Colonização e reforma Agrária (INCRA) e de outras fontes, quando ela pode procurar e se beneficiar dos fundos do governo para construir escolas e outras infraestruturas, e assim por diante. É claro que o MST também se esforça para superar o capitalismo liberal como um todo, e, portanto, tem uma relação muito mais ambivalente com o estado brasileiro do que a mera legalização e obtenção de apoio de infraestrutura pelo INCRA e outras instituições estatais. Mesmo assim, tal como acontece com a personalidade singular, o reconhecimento comum de direito exclusivo é uma

13 Essa noção de direito tem raízes no argumento Hegeliano para "o reconhecimento mútuo" na Fenomenologia de Espirito, especialmente capitulo quatro, "Autoconsciência", e capitulo seis, "Espirito". 
condição necessária para o pleno desenvolvimento de um assentamento do MST ou da CPT. Podemos acrescentar aqui o fato de que a plena realização do assentamento se dá quando este é reconhecido por uma sociedade socialista.

O direito à autonomia dos povos indígenas, no entanto, é uma questão significativamente diferente. Esses povos já existem por tempos "imemoriais". Além disso, o estado brasileiro foi, durante séculos, integracionista, se não mais agressivamente genocida, com respeito a esses povos. Somente na Constituição Federal de 1988 o direito de autonomia e autodeterminação dos povos indígenas no Brasil foi reconhecido num sentido substantivo (veja: Marés, 1988: 90-1; para um resumo excelente). Esses povos indígenas, em outras palavras, obviamente, preexistiam a formação do estado brasileiro, incluindo os interesses econômicos que o estado tipicamente representa. De fato, o estado tem sido sempre a maior ameaça à autonomia dos povos indígenas. Desde o genocídio original dos povos indígenas nas Américas até as tentativas persistentes de os abolirem ou integrarem, 0 estado vem exercendo a maior violência contra essas comunidades. $\mathrm{O}$ reconhecimento pelo estado do direito dos povos indígenas na Constituição Federal de 1988 é uma autolimitação do poder do estado que vai, esperamos, ajudar a criar as condições que permitirão a essas comunidades sobreviver.

Os quilombos parece representar um caso intermediário. Formados além das margens do poder do estado por afro-brasileiros sequestrados da África e que tiveram a sua cultura africana violentamente perseguida e, às vezes, completamente apagada, constituíram novas culturas, economias e políticas além e apesar do poder do estado.

Como nos casos do assentamento do MST e da reivindicação dos povos indígenas à autonomia, o direito coletivo no caso dos quilombos é importante. Em todos esses casos, o estado e os seus órgãos são, assim, transformados de uma força hostil (ou, pelo menos, uma força indiferente, dependendo da situação), para algo que pode ajudar, cultivar e proteger os povos e comunidades tradicionais. Claro, os povos e comunidades tradicionais nunca podem confiar no estado. Este vai sempre ter a tendência de ofuscar, ignorar ou mesmo trair os povos e 
comunidades tradicionais. A luta pelo reconhecimento de um direito é seguida pela luta de aplicá-lo.

Para concluir essa seção, o reconhecimento dos direitos individuais confere, em essência, o respeito e a proteção à autonomia, à irredutibilidade de cada ser humano. Como pessoas, nós não somos redutíveis às nossas comunidades, crenças, práticas ou posições. No entanto, isso significa que o "logos" fundamental dos direitos em geral é o de reconhecer a irredutibilidade, a diferença em si. A extensão do direito de irredutibilidade aos povos e comunidades tradicionais é, portanto, um aspecto do cumprimento do discurso dos direitos, não a sua revogação ou limitação. Isso não significa que os direitos individuais e coletivos sempre coexistem harmoniosamente, longe disso, mas essas tensões não podem ser resolvidas por uma escolha entre o indivíduo e a comunidade. Cada caso deve ser negociado em seus próprios termos.

\section{EXPLORAÇÃO E A AUTONOMIA DOS POVOS E COMUNIDADES TRADICIONAIS}

Mas, o que o discurso dos direitos das pessoas singulares e dos povos e comunidades tradicionais têm a ver com a propriedade dos meios de produção e a exploração? Para Marx, aqueles que não possuem os meios de produção devem vender sua força de trabalho como mercadoria. Eles, inevitavelmente, produzem mais valor através de seu trabalho do que recebem em salários. A diferença entre os salários que eles recebem e o valor que eles produzem é a medida da sua exploração. Mesmo que eles formalmente firmem contratos com seus empregadores por "sua própria vontade", quando vendem sua própria força de trabalho, eles são de fato forçados a vender seu poder de trabalho por falta de qualquer outro meio de vida. Como Marx deixa claro, a propriedade privada dos meios de produção é necessária para a possibilidade de exploração (Marx, 1990: 283-333) Aqui, o discurso dos direitos e liberdade esconde e, até certo ponto, facilita o exercício brutal de dominação. 
No entanto, mesmo se Marx tem razão sobre a natureza da exploração do trabalho assalariado e a sua ligação com a propriedade privada dos meios de produção, não é justificado se reduzir o discurso dos direitos a um véu ideológico que artificialmente sobrepõe a dominação de classe e exploração. Podemos ver isso se nos voltarmos para um estudo de um direito individual em particular, o direito de propriedade privada.

Argumentei acima que o direito individual é o acordo de uma coletividade de respeitar o fato de que a pessoa singular é irredutível a essa coletividade. Isso significa que o direito individual só pode ser realizado e exercido através do cultivo coletivo da comunidade. Dado que qualquer direito individual é um acordo da coletividade, segue-se que o direito à propriedade privada também decorre do mesmo tipo de acordo coletivo. ${ }^{14}$ Parte da irredutibilidade de pessoas singulares é sua necessidade de excluir outros do uso de coisas. Eu devo ser capaz, por exemplo, de excluir outros do alimento que eu como ou do espaço que eu ocupo. Assim, o direito da propriedade privada surge quando o resto da minha comunidade reconhece o meu direito de excluí-los do uso de certas coisas ou espaços. Considerado nesta luz, a mesma tensão interessante emerge aqui como emergiu quando consideramos o direito em geral na seção anterior. Além disso, assim como em nossa consideração sobre o direito da pessoa singular em geral, em que vimos que esse direito só pode ser realizado através de seu cultivo por parte da comunidade, podemos agora afirmar o mesmo ponto em relação à propriedade privada. Efetivamente, na propriedade privada, a comunidade decide como ela vai dividir os bens e os serviços que pertencem a ela entre todos os membros da comunidade. Propriedade privada é um ato coletivo de auto-exclusão. Mas se isso é verdade, no entanto, duas coisas seguem. Primeiro, a propriedade deve ser primordialmente comum. Segundo, a propriedade privada não existe em si. É, na realidade, somente um sistema de justiça distributiva dos bens que são propriedade da comunidade inteira. Dizendo isso de outro jeito, se toda produção é feita coo-

14 É por isso que Marx defende a noção que cada sociedade é implicitamente uma democracia e que, então, a democracia é a plena realização da liberdade humana. Critica da Filosofia de Direito de Hegel (§279). 
perativamente por parte de todos, os produtos pertencem a todos. Toda propriedade é primordialmente propriedade comum. E o que é a definição do direito de propriedade comum? Propriedade comum significa que cada pessoa tem um direito a uma parte desse bem-comum-um direito de excluir outros membros da comunidade de $a \operatorname{lgo}{ }^{15}$. Podemos facilmente ver aqui que a propriedade chamada "privada" é, na realidade, um modo de propriedade comum. Em suma, a condição necessária para qualquer forma de exclusividade da propriedade privada é uma forma mais primordial de propriedade comum. Claro, poucas sociedades que defendem a propriedade privada reconhecem esse fato, mas, mesmo assim, toda propriedade privada é uma manifestação da propriedade comum. Essa é a base também do argumento Marxista de que toda produção é social.

Se toda propriedade é primordialmente comum, o chamado direito à propriedade privada dos meios de produção está em contradição com a própria noção de direito, uma vez que todo bem é primordialmente um sistema coletivo de reconhecimento mútuo. A relação entre a noção de direito e o monopólio dos meios de produção da classe burguesa não é, como pensava Marx, um véu artificial de liberdade que esconde de vista uma verdade mais profunda de coerção e exploração (embora isso certamente aconteça). Uma análise detalhada do conceito de direito revela que o monopólio dos meios de produção é injusto precisamente porque está em contradição com a própria noção de direitos, dado que toda propriedade é verdadeiramente comum. Não há direito "natural" de possuir qualquer propriedade privada, muito menos o meio exclusivo de uma minoria da comunidade de explorar o valor produzido pelo trabalho da maioria. Toda a comunidade tem o direito de decidir como a sua riqueza comum será dividida. Na verdade, a prioridade da propriedade comum é a primeira premissa decisiva de qualquer e todos os regimes de justiça distributiva. Mas, isso nos leva a mais uma conclusão. Se toda propriedade é primordialmente

15 Estritamente falando há "propriedade comum" no capitalismo. Os acionistas de uma empresa têm a "propriedade comum" das terras que exploram, poluem e abandonam. Por propriedade comum aqui, no entanto, eu quero dizer o tipo de relação recíproca e cooperativa entre os membros da comunidade e a natureza que eu brevemente discuti na Introdução. 
comum e se a comunidade tem o direito de controlar o jeito que os bens comuns são distribuídos, devemos concluir também que deveria existir um direito comunal aos meios de produção. A propriedade comum dos meios de produção é um direito humano.

Vamos, então, trazer essa discussão de volta para uma consideração dos povos e comunidades tradicionais, incluindo os movimentos sociais que lutam pela reforma agrária. Muitos povos indígenas, por exemplo, ainda tem controle coletivo (dividido em várias formas) dos meios de produção. Isso não presume que essas comunidades não têm formas de dominação e poder dentro delas, mas significa que a maior parte delas não é construída sobre uma base de exploração de classe. Isso é o caso para os povos indígenas, como os Guarani-Kaiowá do Mato Grosso do Sul que estão tentando preservar a terra que tem sido deles por tempos imemoriais, ou para os posseiros do Ceará rural tentando estabelecer um direito claro de terreno onde eles têm morado e trabalhado por gerações ou, na verdade, como assentados do MST que ocuparam e se estabeleceram na terra que não conseguiu cumprir a sua "função social" estabelecida pelos artigos 184 e 186 da Constituição Federal de 1988. Assentamentos do MST são um caso claro. A terra do assentamento pode pertencer como propriedade ao INCRA ou à associação do assentamento em si, mas a terra de cada assentamento é divida segundo a decisão coletiva da associação do assentamento. Às vezes eles decidem por dividir a terra em lotes familiares e, outras vezes, escolhem trabalhar em cooperativas de produção. Mas, uma coisa unifica esses dois modos: a associação do assentamento toma para si essa decisão, dividindo assim um bem primordialmente comum. Do mesmo jeito, há frequentemente áreas comuns ou ferramentas e máquinas compartilhadas, bem como mutirões e outras formas de cooperação. Assentamentos do MST, em outras palavras, expressam literalmente a prioridade da propriedade comum (dado que a distribuição é determinada coletivamente) e a dependência da propriedade privada na propriedade comum (Diniz e Gilbert, 2013).

$\mathrm{Na}$ verdade, uma razão decisiva pela qual os povos e comunidades tradicionais conseguiram preservar ou construir uma identidade que 
requer a proteção por direitos é precisamente que muitos entre eles controlam os meios de produção. Eles são tipicamente comunidades, como acabei de mostrar no caso do MST, que são estruturadas e motivadas por relações de cooperação entre os seus membros ou, pelo menos, pela propriedade dos meios de produção pertencente à maioria dos membros. Pescadores no Ceará não precisam pescar em conjunto, mas, cada família é proprietária do barco, das redes e de outras ferramentas que lhes permitem ser autônomos. Claro, eles também têm acesso ao mar. Com efeito, a autonomia dessas comunidades, em geral, é parcialmente construída sobre uma base de sua autonomia econômica. Se povos e comunidades tradicionais não são economicamente dependentes da cultura dominante em geral, e, portanto, são também independentes da exploração capitalista, eles já percorreram um longo caminho para preservar a sua autonomia social, cultural e político. Há muita variedade no espectro de povos e comunidades tradicionais no Brasil a respeito de como o controle autônomo sobre os meios de produção é exercido, mas, na maioria, se não em todos os casos, isso significa uma espécie de reciprocidade não-exploradora e coletiva entre os membros da comunidade e com a natureza. A essa luz, os direitos à terra (incluindo à beira-mar para os ribeirinhos) não são apenas uma questão de quem deve ou não ter direito legal a uma determinada extensão da propriedade, mas são uma condição necessária para a possibilidade da autodeterminação econômica desses povos. Os direitos à terra dos povos indígenas, por exemplo, devem ser suficientemente extensos e suficientemente bem protegidos a fim de que os seus modos tradicionais de caça, pesca, coleta e agricultura possam realmente satisfazer suas necessidades básicas. Comunidades de pescadores devem ter o controle efetivo sobre as praias onde eles guardam suas jangadas e outras embarcações de pesca, bem como ter acesso ao mar. Quilombos e assentamentos de reforma agrária devem ter acesso a boa terra arável e às ferramentas e outras necessidades para ganhar a vida na terra.

Em cada caso, além disso, a sustentabilidade da natureza é em si uma condição necessária para o bem-estar da comunidade. Isso está em contraste gritante com as grandes corporações que podem extrair 
e destruir os recursos naturais de uma região, após isso abandoná-la, e mover suas operações para outros lugares. A essa luz, povos e comunidades tradicionais, incluindo assentamentos do MST e CPT, são frequentemente modelos do único futuro humano possível: um em que podemos superar a exploração avarenta e o crescimento infinito do capitalismo (alimentado pela concorrência), para criar uma relação sustentável e recíproca com a natureza.

Joaquim Shiraishi Neto argumenta que existem duas características decisivas da autodeterminação dos povos e comunidades tradicionais. Eles devem, em primeiro lugar, ter "o direito do grupo definir o que quer, o que quer para si, ou seja, de definir suas prioridades quaisquer que sejam; e, segundo, o direito de participar de todas discussões que lhes possam afetar direta ou indiretamente." É importante destacar que isso inclui, "o fato de garantir que os sujeitos se definam a partir de sua própria consciência, rompe com uma maneira de pensar o direito, alargando a compreensão das 'práticas jurídicas', que se encontram referidas ao campo jurídico” (2007: 50). Gostaria, portanto, de colocar um terceiro direito necessário. Povos e comunidades tradicionais devem ter o direito de possuir ou, pelo menos, ter o controle efetivo dos meios de produção. Em um sentido, a Constituição Federal de 1988 do Brasil, no artigo 231 , parágrafo $1^{\circ}$, já sugere uma espécie de direito aos meios de produção para os povos indígenas:

[s]ão terras tradicionalmente ocupadas pelos índios as por eles habitadas em caráter permanente, as utilizadas para suas atividades produtivas, as imprescindíveis à preservação dos recursos ambientais necessários a seu bem-estar e as necessárias a sua reprodução física e cultural, segundo seus usos, costumes e tradições (BRASIL, 1988).

É meu argumento, porém, que deveríamos lutar para o direito aos meios de produção para todo mundo e, de fato, para todos os seres humanos. 


\section{CONCLUSÃO}

O desafio dos povos e comunidades tradicionais, incluindo lutas pela reforma agrária no Brasil, exemplifica questões-chave que enfrentam toda a humanidade. Como podemos criar uma sociedade justa em que os direitos dos indivíduos e das comunidades sejam reconhecidos pelas comunidades mais amplas de uma maneira que também estabeleça uma relação de reciprocidade com a natureza e que impeça a exploração?

A tradição dos direitos humanos protege as pessoas contra toda uma série de formas de abusos, e a tradição Marxista visualiza uma sociedade sem exploração econômica sistemática. As duas surgiram a partir dos impulsos mais profundos e mais fortes da busca humana por justiça. Elas também têm sido usadas para esconder ou até mesmo cometer injustiça.

As reivindicações de direitos de povos e comunidades tradicionais, por isso, não são apenas as tentativas de criar uma sociedade mais tolerante que pode abraçar diferença cultural dentro dela, mas uma luta para o coração da própria justiça. Nas palavras de Carlos Marés, os povos e comunidades tradicionais "na luta pela sua manutenção e reconhecimento de direitos, especialmente territoriais (que incluiu terra e a natureza que nela vive, isto é, que não substitui a natureza pelo valor terra/mercadoria), enfrentam o capital e são, de fato, anti-capitalistas." ${ }^{6}$ Se os direitos individuais não são estendidos aos povos e comunidades tradicionais e o seu direito não inclui o direito aos meios de produção, a luta pela justiça é diminuída ou mesmo traída.

A demanda dos povos e comunidades tradicionais é, portanto, que as tradições de direitos humanos e de resistência à exploração econômica possam ser ativas na extensão dos direitos existentes e na criação de novos direitos, incluindo novos direitos para além do que temos reconhecido até agora em noções ocidentais de direito.

16 Correspondência privada, 10 dezembro, 2015 


\section{REFERÊNCIAS}

BOURDIEU, Pierre. A força do direito. Elementos para uma sociologia do campo jurídico. In: BOURDIEU, Pierre. O Poder Simbólico. Trad. de Fernando de Tomaz. Rio de Janeiro: Bertrand Brasil S.A., p. 209-254, 1989.

BRASIL. Constituição da República Federativa do Brasil. Brasília: Casa Civil, 1988. Disponível em: http://www.planalto.gov.br/ccivil_03/Constituicao/ConstituicaoCompilado.htm, acessado em 14 de maio de 2016.

DINIZ, Aldiva Sales; GILBERT, Bruce. Socialist Values and Cooperation in Brazil's Landless Rural Workers Movement. In: Latin American Perspectives, 40 (4), p. 19-34, 2013.

HABERMAS, Jürgen. Between Facts and Norms: Contributions to a Discourse Theory of Law and Democracy. Trad. William Rehg. Cambridge: The MIT Press, 1996.

HEGEL, G. W. F. Phenomenology of Spirit. Oxford: Oxford University Press, 1977.

. F. The Science of Logic. Trad. George Di Giovanni. Cambridge: Cambridge University Press, 2010.

MARX, Karl. Capital: A Critique of Political Economy (Vol. One). Trad. Ben Fowkes. London: Penguin Books, 1990.

- The Portable Karl Marx. Tradução de Eugene Kamenka. New York:Penguin Books, 1983.

NETO, Joaquim Shiraishi (Org.). Direito dos Povos e das Comunidades Tradicionais no Brasil: Declarações, Convenções Internacionais e Dispositivos definidores de uma Política Nacional. Manaus: Projeto Nova Cartografia Social da Amazônia, 2007.

RAWLS, John. A Theory of Justice. Cambridge: Harvard University Press, 1971.

SOUZA FILHO, Carlos Frederico Marés de. O Renascer dos povos indígenas para o direito. Curitiba: Juruá, 1998. 